\title{
Project Teaching Method in Applied Universities Computer
}

\section{Network Course}

\author{
Xin-ling Feng \\ Zhengzhou University of Industrial Technology, the School of Information \\ Engineering, ,Henan, China, 451100
}

\begin{abstract}
Students improve computer knowledge and practical ability, it is the fundamental task of applied undergraduate colleges computer education. Due to which the unit is applied to private colleges and universities, private undergraduate colleges Students learn foundation is weak, poor computer teaching efficiency, the use of project teaching law courses at private colleges and universities in the computer network is very necessary.
\end{abstract}

Keywords: Project Approach Teaching Computer network Course Cabling project Introduction:

Teaching computer network curriculum, teacher education management and more traditional teaching mode. First, the content of the concept of computer networks, development, and other hardware components are introduced; Secondly, TCP / IP protocol, OSI seven-layer model, a variety of network functions; finally, introduce network applications and network security precautions and other knowledge. This traditional teaching model seems to have been the teacher of computer network knowledge to teach all students, but in fact, vocational school students just learned how the Internet, as to how to manage and maintain a network still no from the start. Therefore, to allow students to receive knowledge and skill in one of education, improve students' computer knowledge and practical ability, can give full play to the use of the student body and the innovative teaching method, and achieved good results.

\section{Project Approach}

Constructivist learning theory, knowledge is not obtained by the teachers teach, but students in certain situations, with the help of others (including teachers and students) help with the necessary learning materials, through the construction of meaning in the way. Based on the requirements of constructivist pedagogy, students in the learning process, you want to own the center, in order to help the teacher role, the use of scenarios, collaboration, conversation and other elements of the learning environment to enable students to give full play to the body and the spirit of innovation, to enable students to effectively reach the current knowledge on the significance of the construction.

Teaching project is under the guidance of constructivism, the actual projects targeted, first by the decomposition of the project teachers, and appropriate model, and then the students into groups around their projects for discussion, collaborative learning, and finally common case of completed projects to evaluate whether students achieve a new teaching method for teaching purposes. Teaching project for vocational school students quality is generally not high, through demonstration projects to equip students with the most basic knowledge, learning and set up a new fulcrum of knowledge and use of knowledge transfer, collaborative discussion to complete the construction of the meaning of knowledge.

2. The project - teaching cases

Project teaching requirements in the teaching process, in order to complete a concrete project for clues, the teaching content being subtly implied in each project, to enable students to identify 
problems in their own practice, and through independent thinking and the guidance of teachers, to solve problems, learn self-learning methods. According to the network characteristics of the course, we combine the actual cabling system project construction process to establish integrated wiring technology knowledge architecture, including cabling system design, budget, construction, testing and acceptance, so that each knowledge module covers students should master engineering knowledge, through project teaching to reflect the practical application of this knowledge modules.

Students visit the model engineering and design, budget, construction, testing and acceptance of five learning modules knowledge, practical grasp from design to testing and acceptance necessary skills, the ability of enterprises to meet the requirements of talent. The entire teaching process, students need hands to achieve teaching objectives. Students complete hands-on process, analyze problems, problem-solving skills improved, independent exploration and cooperative learning awareness has been strengthened.

2.1 Project Approach as the practice of teaching

Four teaching method:

(1) Prepare. At this stage should first determine the problem and clear the purpose of teaching, students are divided into groups, and then select the instruments of labor and materials, and to arouse students' interest.

(2) Demonstration. Practice by the instructor demonstrate the steps slowly, but demonstrates what to do and how to do so, pointing out errors may occur, emphasizing the focus on labor safety tips.

(3) Like to do. Students work according to the steps at the side of the instructor explained, inspections and correct large errors, while giving assistance, recognition can correctly grasp the essentials of students, encourage students backward.

(4) Application. Given by the instructor application exercises, students solve problems on its own, it requires not only correct, but also more skilled to be able to quickly solve the problem. Instructor edge guide side to correct the error, praise to encourage the progress of students, and students through conversation, ask questions, check the quality of work, etc. Evaluation of results. In the process of teaching practice, not only to train students to practice basic skills of operation, occupation (job) professional skills, but also focus on the students basic professional qualities, when including punctuality, punctuality and sense of responsibility, work attitudes, norms training, cooperation with others, coordination, communication ability, independent planning, organization, ability to implement, discovery, analysis and problem-solving abilities.

2.2 The establishment of field engineering simulation teaching environment

The students involved in real environment, help to develop students' ability to solve practical engineering problems. Establish real professional environment in accordance with the principle of "to create atmosphere of the scene, improve the practical capacity", so that students in a real environment, job requirements, work procedures, standards, regulations and the project site is consistent, according to the professional post group on basic skills requirements, practical training and the overall quality of training, so that students master the ability to solve practical problems.

Training and equipment should be first-line use of engineering equipment, tools, equipment consistent. Computer network simulation project site teaching environment introduced very advanced FLUCK test equipment (DTS1200), fiber welding machine, all kinds of cabinets patch panels, LIU, switches, outdoor fiber, 6, 5, UTP, a large number of cables, each commonly used 
tools and equipment modules, crystal head, pipeline bridge. Training programs and to truly reflect the integrated wiring engineering design, installation, commissioning, testing and acceptance of unity. Training process, first by the teacher gives a typical building basemap, designed by students cabling system that requires students to use AutoCAD or Visio software to map out various types of cabling design files, including the design of general information, the main material equipment list, total plan, each floor flat drawing and weak pipeline embedded; according to the construction, pipeline drawings using tools wiring installation equipment on the floor between the level of a certain link pipeline laying, one workspace to install, use FLUCK test apparatus an installation of a good line, good acceptance documented. Training programs using new technologies, new processes, reflecting the advanced nature of areas of expertise, so that the graduates can adapt to the current employment requirements.

3.The project teaching practice in particular should pay attention to the problem

Project teaching, learning process for everyone involved to become a creative practice, not the final result of its focus, but to complete the process of the project. In practice projects, teachers should pay attention to the following issues:

3.1 To establish practical, excellent project.

Establishment of the project is not just an easy thing. First of all, the project should include all the teaching content and as naturally as possible, organically combined with a number of knowledge points; secondly, the degree of difficulty of the project to determine the actual level of the students; the third project to be like most students, and can administered fairly and accurately evaluate the use of a standard. Of course, not every project can be exhaustive, teachers should be to establish the most suitable items according to the specific training direction.

3.2 Establishment of project activities groups to properly depending on availability.

Project by students independently, or group cooperation to complete, according to the specific characteristics of the project to establish. Through teaching practice repeatedly to draw: pure knowledge for a new project to students to complete more appropriate; and involving a wide range of knowledge, more difficult projects, will have to group collaboration, because students each a director of complementary knowledge can help them solve more problems.

3.3 The guidance of teachers to be just right.

Students encounter difficulties in the process of completion of the project, should be timely guidance. Depth guidance for different levels of students, teachers should be different. Teaching the fundamental purpose of the project is to allow students to discover their own knowledge and skills, so teachers must grasp the scale of the guidance. Even if the student has a problem, it should be instructive, non-positive, non-comprehensive guidance prompts enable students not only memories, but also exercise the students' divergent thinking, to develop their ability to innovate.

Conclusion:

Project completion process is the students themselves to explore the process of study, in order to learn all long, summed up after the completion of the project is also very important. It should include a summary of ideas and skills summary. Summarize ideas can help students clarify the best way of thinking of the completion of the project, to find their theoretical deficiencies. Skills summary, "a given problem" should be strongly recommended, regardless of the difficulty of each method should be presented to students by teachers and students together and then evaluate the advantages and disadvantages of each method and the scope of application, so that students can learn more operating skills, fully absorb the essence of the entire project activities. 


\section{References:}

[1] Zhao Jianhua. Collaborative learning and collaborative learning [J]. China Educational Technology, 2000, (10).

[2] OPINIONS Zhangqing Bin. Cabling system installation [M]. Electronic Industry Press, 2006.

[4] Ling Ruiz. Website development stages of education [j]. Theorists. 2005 (08)

[5] Fang Yihua. Web design of small education [j]. Journal of Mudanjiang College of education. 2005 (06)

[6] Li Weenie. Basic elements of education website construction [j]. Michelangelo education (consolidated version). 2004 (16) 